\title{
Notas Sobre Beyond Scenography
}

\author{
Rachel Hann ${ }^{1}$ \\ Northumbria University, Newcastle, United Kingdom \\ E-mail: dr.rachelhann@gmail.com \\ Tradução de Fausto Roberto Poço Viana \\ Universidade de São Paulo - USP, São Paulo/SP, Brasil \\ E-mail: faustoviana@uol.com.br
}

\section{Resumo}

Abstract

Este artigo documenta a palestra 'Scenographic Futures', apresentada como parte da sessão PQ TALKS, na PQ 2019, uma declaração de posição chamada 'Changing the Question' é apresentada para refletir se, em vez de perguntar o que é cenografia, agora a pergunta é o que a cenografia faz? Como a cenografia afeta, canaliza e orienta experiências de palco, lugar e mundo.
This article document the lecture 'Scenographic Futures', presented as part of the session PQ TALKS, at $P Q 2019$, a position statements called 'Changing the Question' is presented to reflect if rather than asking what is scenography, now the question is what does scenography do? How scenography affects, channels, and orientate experiences of stage, place, and world. 
Em 2019, publiquei meu primeiro livro chamado Beyond Scenography (Além da cenografia). Escrevi o material ao longo de cinco anos, mas ele na verdade começou depois da minha experiência na $P Q 2011$. Meus dez dias em Praga foram gastos principalmente trabalhando em uma igreja dessacralizada, como parte de um Laboratório de Espaço, organizado por Dorita Hannah. Nosso objetivo era discutir o futuro da arquitetura teatral. Vinte e um de nós de todo o mundo estávamos reunidos para compartiIhar, debater e propor novas ideias. Não fomos bem sucedidos. Houve diferenças significativas na forma como os termos como "cenografia" foram abordados, mas também como as técnicas do palco associadas a este termo eram praticadas de forma diferente em diferentes países. Muito tempo foi gasto discutindo nossas diferenças provocadas pelo uso em termos em inglês em outros idiomas. Com base nessa experiência, eu queria escrever um livro que abraçasse essa ideia de diferença. Uma ideia que sugere a maneira com que a cenografia é praticada e as formas pelas quais a cenografia se articula estão conectadas. Particularmente em relação às línguas continentais europeias, cada uma tem uma grafia ligeiramente diferente para cenografia e nenhuma delas tem a letra "y" no final (como no inglês). Dessa forma, eu queria reconhecer que a apropriação da língua inglesa não era a cenografia universal. Esse foi um dos pontos de partida para Beyond Scenography.

Como uma acadêmica, eu mando com frequência artigos para revisão no sistema por pares e, sem dúvida, eu sempre recebo a mesma linha de devolutiva. "É maravilhosamente rigoroso, mas ambicioso demais". Tenho pensado, com alguma constância que deveria fazer uma camiseta onde se leia simplesmente: "Ambiciosa demais". A proposta de Beyond

1 Rachel Hann é cenógrafa cultural que pesquisa as culturas materiais de design de performance, crise climática e performance trans*. Desde abril de 2020, Rachel é professora sênior de performance e design na Northumbria University, Newcastle.

2 HANN, Rachel. Beyond Scenography, Oxon. and New York: Routledge, 2019.
Scenography recebeu o mesmo tipo de, como se descreve frequentemente, "devolutiva mista". Mesmo assim, ele foi comissionado, e por isso eu dou o crédito para Talia Rodgers (então na Routledge, mas agora na Digital Theatre) por acreditar no projeto. Comecei com uma série de perguntas iniciais que buscavam reconhecer a ambição do projeto, juntamente com a ideia de diferença. Isso significava expandir ideias e abordagens conceituais da cenografia de maneiras que excediam algumas ortodoxias do design de cena, que focavam em seis objetivos principais:

1. Abraçar as diferentes compreensões e práticas da cenografia;

2. Resistir a reivindicar o inglês como o uso definitivo;

3. Abraçar a cenografia como estando igualmente preocupada com som e traje de cena, bem como cenário e iluminação;

4. Imaginar como podemos falar sobre cenografia além de uma posição centrada na visão;

5. Refletir sobre como os cenógrafos tinham sido a voz dominante da cenografia e como o quadro conceitual mudaria se fosse considerado o ponto de vista disciplinar de outros membros da equipe de produção;

6. Abraçar plenamente as contribuições que a teoria pode oferecer para o futuro da prática cenográfica.

Baseada nesses objetivos, escrevi um livro para alguém exatamente como eu, que é igualmente seduzido por teoria. Acredito que teoria é emocionante. Uma "grande ideia" pode literalmente mudar vidas, economias e futuros. No entanto, eu também percebo que a teoria pode ser altamente técnica. Para ajudar nisso, também tenho um canal no YouTube (HANN, 2020) baseado no livro. O livro é destinado a um público que, como eu, não saiu da biblioteca da universidade na melhor parte de 15 anos. A série do YouTube tem o mesmo nome do livro e procura articular algumas dessas ideias que esclareciam o projeto para um público em geral. 
Não tenho certeza do sucesso exato da série em alcançar esse objetivo, mas ela mistura a palestra acadêmica com a comédia. Em preparação para a PQ2019, editei um episódio que foi dividido em nove declarações sob o título de "Futuros Cenográficos". O primeiro deles foi "Mudando a pergunta". Em vez de perguntar o que é cenografia, agora a questão é o que a cenografia faz? Como a cenografia afeta, canaliza e orienta experiências de palco, lugar e mundo. Isso para mim é crucial em termos de reconhecer para onde vamos no futuro teoricamente, mas também abraçar de onde viemos. A ideia de diferença era uma parte central desse argumento.

A premissa básica dos meus próprios argumentos teóricos tomou, como ponto de partida, que se algo pode ser coreografia e coreográfico, performance e performativo, teatro e teatralidade, dramaturgia e dramatúrgico, cinema e fílmico, então algo também pode ser cenografia e cenográfico. Eu estava interessada em considerar o que acontece se algo é cenográfico, mas não é necessariamente cenografia. Um exemplo disso pode ser uma árvore de Natal. Uma leitura dela pode indicar que seja um objeto altamente cenográfico, mas ela não foi necessariamente criada por cenógrafos de palco. Essa abordagem posiciona a "cenografia" como algo que ocorre como parte de uma "performance estética". Coisas ou eventos que tenham um lugar similar na orientação de qualidades, mas que ocorrem além deste limite, seriam considerados "cenográficos". Assumindo que essa leitura tivesse um grau de validade, percebi desde cedo que precisaria resistir à ideia de escrever, em qualquer lugar do livro, a ideia de "o cenográfico" como definitiva. Tomei essa decisão por duas razões: 1) ao utilizar o definitivo torna-se monolítico, torna-se essencialista. Eu queria explorar as possibilidades de uma abordagem cenográfica, mas também queria evitar defini-la de forma redutiva e pouco generosa. Lembre-se que um dos meus objetivos era abraçar as diferentes abordagens da cenografia através das fronteiras linguísticas e culturais; 2) minha própria experiência com a cenografia sempre foi uma combinação de design de figurino, design de iluminação, design de som e design de cenografia. Eu via a intersecção dessas práticas como a marca da cenografia. A cenografia sempre foi plural. Nunca foi singular. Comecei então a pesquisar as histórias de "performativo" como uma ideia. Me deparei com a apresentação de J. L. Austin na Universidade de Gotemburgo em 1959, que foi intitulada "Performativos". Pensei que se Austin (1962) pode falar sobre performativos, então eu posso falar sobre cenográficos. Vou colocar um 's' no final, e isso desloca o meu problema de usar o cenográfico como definitivo. Depois disso, descobri que Darwin Reid Payne já havia proposto brevemente uma ortografia semelhante como parte de seu livro de 1994, chamado Computer Scenographics (PAYNE, 1994). A partir do parágrafo curto de Reid Payne sobre a definição do termo, abordei cenográficos como elemento central para articular, defender e propor novos caminhos disciplinares para o estudo da cenografia.

Foi assim que a ideia de cenográficos surgiu no livro. Isso aconteceu realmente muito tarde, mas ainda assim me permitiu falar sobre múltiplas técnicas de palco e peculiaridades que andam juntas. O que eu procurava atingir através do conceito de cenográficos era articular os efeitos acumulativos da cenografia enquanto produzida por uma família de perspectivas, técnicas e práticas que andam juntas. Essa abordagem também teve o objetivo secundário de oferecer uma ponte conceitual que traz outros colegas que trabalham com estudos de teatro e performance dentro do escopo da cenografia. Mesmo que, anteriormente, aqueles que se concentram em atuar ou dirigir tenham tratado sobre encenação ou cenografia, raramente eles usavam o termo "cenografia" e quando o faziam muitas vezes ignoravam qualquer literatura sobre o assunto. Essencialmente, para aqueles que estudam peças e até mesmo teoria da performance, havia uma percepção de que a cenografia não era para eles. Eu queria proporcionar uma discussão renovada que convidasse esses colegas para o debate e procurasse ir além da ideia da cenografia como sendo apenas para designers.

Para conseguir uma ponte conceitual e acolhe- 
dora de outras partes, decidi ser ousada e abraçar um conceito do qual ambas as partes ou não gostavam ou ignoravam: o de "mundano". Que é diferente de "do mundo", que é definitivo. A ideia de mundano abraça a coisa que pode ser descrita como "do mundo" como sempre estando em processo. Essa abordagem se constrói diretamente a partir de ideias de novo materialismo, que abrangem as noções de indeterminação, pensamento ecológico, teoria da montagem e pensamento não binário. Por exemplo, a proposta de Donna Haraway (2016) de que estar com é um ato radical que trabalha contra histórias de filosofia que demarcam os humanos como além ou fora da "natureza". A abordagem de Haraway rejeita os binários ontológicos rigorosos do sujeito e do objeto, humano e mundo, subjetivo e objetivo. Os ontologismos planos do novo materialismo proporcionam uma compreensão dos humanos como sendo parte de um conjunto mais amplo de coisas que têm poder sobre nós, como nós temos poder sobre elas. No entanto, o humano não é excessivamente privilegiado dentro dessa matriz. Em vez disso, permite uma estrutura teórica a partir da qual se especulam abordagens renovadas para as relações homem-mundo, que abraça a ideia de que não existe "o mundo" - há apenas o mundano como um processo contínuo. A mudança é o parâmetro fixo.

Com base nessas novas ideias materialistas, decidi reexaminar a noção de "do cênico" e sua relação com o "pitoresco". Em particular, defendo que a estética do pitoresco é uma estética de distância ontológica. Como tipificado por uma pintura paisagística, o sujeito (humano) humano observa o objeto (mundo) a partir de uma distância. Como exemplo de pensamento binário, essa estrita ontologia do sujeito-objeto situa os seres humanos como uma entidade separada que observa a paisagem a uma distância crítica. Os humanos não estão com a paisagem neste modelo estético. No novo materialismo, os humanos são sempre parte de assembleias mundanas. Os humanos nunca estão fora do mundo como um processo. Um bom exemplo disso na prática é o uso de áreas projetadas para ver a paisagem ou uma "vista cênica", muitas vezes em uma beira de estrada ou em um parque público. A maneira pitoresca de abordar essa tarefa estética é olhar sobre o mundo, mas eles mesmos estão removidos do mundo. Neste caso, o mundo é imaginado como algo que pode ser consumido como um recurso para o prazer humano. Para criticar essa abordagem, em vez disso, abracei a ideia de 'coesão' como sendo central para cenográficos. Esta abordagem é semeIhante à de Adolphe Appia em 1921, afirmando que o teatro do futuro será a diferença entre ver uma jovem correndo por um campo, e correr de mãos dadas com ela. Ainda que fosse possível interpretar isso literalmente como teatro imersivo, em termos de cenografia mesmo quando sentados em um auditório, os humanos estão sempre conectados com a arquitetura, com nossos assentos, com a iluminação, com o som, com o público, com os performers, com o cenário, com a política do exterior. Eu argumento que a coesão é central para todos os eventos cenográficos, seja jardinagem ou mesmo em cosplay, e que essa coesão não é uma propriedade exclusiva do teatro imersivo. Minha proposta de coesão dos cenográficos busca exemplificar outra forma de abordar a estética das cenas além do pensamento binário.

Neste ponto, quero refletir mais sobre a ideia de mundano. Kathleen Stewart é uma antropóloga que trabalha no Texas e ela tem escrito muito sobre a ideia de mundo e multiplicidades do mundo.

Aqui, a teoria composicional toma a forma de uma sintonia acentuadamente impassível às maneiras pelas quais um conjunto de elementos vem a se unir como algo que tem qualidades, estética sensorial e linhas de força e como tais coisas fazem sentido quando já compostas e generativas, colocando matéria e mente para uma concretização: o mundano. (STEWART, 2014, p. 119).

Eu fico fascinada pelos modos com que os cenográficos podem intervir e irritar as estruturas do mundo e, ao fazê-lo, lembrar-nos que o mundo sempre esteve em processo. Que a humanidade faz parte do mundo, e o mundo não é para a humanidade. 
Um exemplo prático que uso no livro é o de um restaurante em Guildford, no Reino Unido, onde eu morava na época. É um restaurante tailandês da moda que se esforçou muito para recriar a sensação de um mercado de rua de Bangkok, mas é no centro de GuiIdford, uma cidade de classe média. O prédio é uma edificação longa e fina, sem janelas. Eu amava este restaurante. Falo no meu livro sobre o quão altamente sedutor era o design de interiores e como todos as habilidades e sentidos da culinária (cheiro), design (espacial), texturas (hápticos), e sons, todos funcionavam juntos para promover uma certa sensação de atmosfera ou lugar. Eu levei meu pai para este espaço e ele disse "Rachel, eu sei que você está muito interessada em todos esses tipos de coisas, mas veja aquela poeira. Ela é cenográfica também?". Eu balancei a cabeça e disse: "Sim, acho que sim! É tudo parte das qualidades atmosféricas do restaurante. Os detalhes importam". Neste contexto, o restaurante tailandês atuou para orientar uma sensação de Bangkok através de técnicas cenográficas. De fato, orientação é uma concepção fundamental no livro.

Adoto a dupla abordagem de Sara Ahmed para orientação. Extraído de seu livro Queer Phenomenology (AHMED, 2006), orientação é tanto o caso de ser colocado em termos de perto e longe, bem como observar como seu corpo está situado nesses contextos. Quer você esteja com medo ou feliz, familiarizado ou estranhando, ela fala sobre o exemplo de estar em um Posto de Alfândega no Reino Unido, onde por não ter um corpo branco, ela é vista de forma diferente devido às orientações sociais que os outros leem de seu corpo. Ao começar com a heteronormatividade como orientação dominante, Ahmed passa a propor orientações conceituais queer que se estendem à forma como encontramos objetos de uma matriz semelhante de diferença e familiaridade, alienação e tornar estranho. É parcialmente por isso que eu nunca afirmo que os cenográficos criam mundos. De tal forma que os cenográficos revelam as orientações queer do mundo que de outra forma seriam invisíveis. Em vez disso, falo sobre como cenográficos atingem ordens do mundo ao destacar, irritar, mudando como os mundos são conceitualizados como atmosferas afetivas. Os cenográficos são produzidos pela intersecção de narrativas mundiais (o que pertence) e materialidades (o que se materializa). As orientações mundanas estão, portanto, igualmente preocupadas com questões de imaginação como com o desenho de objetos. Nesta descrição está a raiz dos cenográficos - que os cenográficos nos permitem performar o mundo de forma diferente.

Com base na noção de orientações queer, argumentei que os cenográficos são sempre intervencionistas. Como exemplo do que quero dizer com intervenção, me volto a um exemplo, que incluí no livro, que ocorreu na Irlanda do Norte em 2013 como parte da cúpula do G8. Como um grupo de nações que se definem como ricas, os líderes desses países ficaram em um resort de campo de golfe que ficava a aproximadamente 20 minutos de carro do centro de conferências. As comitivas de Obama e Putin teriam vindo rugindo por pequenos lugares como Fivemiletown. Dirigindo potencialmente em altas velocidades e com janelas escurecidas, os líderes do conselho local da área perceberam que eles seriam conduzidos passando por lojas que haviam fechado durante a recessão e nunca reabriram. Só para relembrar o contexto, a Irlanda do Norte tinha sido economicamente esquecida pelo resto do Reino Unido desde 2008 e não havia se recuperado da crise financeira. O povo tinha sido abandonado para passar por uma série de dificuldades com pouco apoio do governo britânico. Nos anos mais recentes, o Brexit ofereceu um novo contexto interessante onde a fronteira norte-irlandesa reentrou na imaginação cultural do Reino Unido como um problema. Enquanto na imaginação norte-irlandesa a fronteira, desde o acordo da sexta-feira santa, tinha se transformado em um ponto de liberdade.

No que diz respeito à cúpula do G8 de 2013, o conselho local viu uma oportunidade para investimento internacional. Para aumentar suas chances, eles contrataram uma empresa gráfica para projetar pôsteres trompe l'oeil, que foram colados nas janelas inteiras das lojas fechadas. Isso fez com 
que parecesse que Fivemiletown e outros pequenos lugares eram locais de capitalismo e comércio prósperos. Havia cartazes que transformavam lojas vazias em açougues, agência de viagens, uma papelaria e uma cafeteria. Quando se passava em alta velocidade, poderia-se ser seduzido a pensar que a Irlanda do Norte era um lugar próspero e poderia permanecer na mente como um lugar para se investir no futuro. Embora possivelmente concebidos com boas intenções, já que o conselho da cidade estava tentando transparecer uma sensação de sucesso, na prática os cartazes funcionaram oportunamente como lembretes de que a Irlanda do Norte é qualquer outra coisa menos bem sucedida. Ao tentar disfarçar o problema, os cenográficos dos cartazes destacaram o problema de uma forma que revelou algo profundo sobre a política do Reino Unido.

Para concluir, meu objetivo com Beyond Scenography era oferecer uma teoria da cenografia. Agora que estou começando os planos para o meu próximo livro, também percebo que ele ofereceu o ponto de partida para como os cenográficos oferecem uma lente sobre como os sentimentos dos mundos são produzidos através de orientações de locais criados. A ideia de mundano cenográfico abre as portas para uma discussão mais ampla sobre como as narrativas mundiais também são "cenográficas" de alguma forma. Sejam ideias do "primeiro mundo" ou "terceiro mundo", "o Oeste" ou "o Sul", essas narrativas mundiais são reforçadas através de uma perspectiva de mundo que muitas vezes é comunicada por meios cenográficos. Pode ser um mapa, uma história, um programa de TV, ou como nossa linguagem enquadra outros locais, povos e eventos. Se essas atividades culturais estão de alguma forma criando um sentimento de lugar, eu argumento que elas também são, pelo menos em parte, cenográficas. Isso segue a ideia de que os cenográficos são orientações de locais criados e, embora explicitamente assim no teatro, agem para outros como as materialidades são ordenadas em termos de mundo.

Um bom exemplo é a escrita criativa. Embora não seja espacialmente baseada em uma práti- ca, estudiosos da literatura e escritores criativos há muito tempo têm consciência de como suas histórias constroem mundos através de um imaginário espacial criado que "parece real". O que é particularmente interessante do ponto de vista teórico é que esses mundos operam de forma semelhante ao nosso próprio "mundo". Eles proporcionam um sentido de outro lugar, que você mesmo não foi fisicamente. No entanto, você pode imaginar sua própria relação espacial com seus povos, lugares e coisas. Isso age na mesma lógica das histórias que nos são contadas sobre outras nações e como elas são amigáveis, hostis ou inferiores. Dessa forma, pode-se dizer que os cenográficos da escrita criativa equivalem à forma como as narrativas mundiais reforçam a política mundial. As cenas do mundo são então comunicadas através de uma série de atividades que, muitas vezes sem querer, estabelecem uma visão do futuro que é singular e imutável. A cenográfica oferece uma perspectiva sobre a comunicação dessas narrativas que inclui o restaurante temático, bem como os gráficos de nossos programas de notícias nacionais. Todos eles trabalham para ter um sentido de mundo.

Os mundos imaginados de ficção criativa não são, como com nossas narrativas do mundo "real", esgotados pela especulação. Por exemplo, no universo de Star Trek você pode entender os programas de TV e filmes como cânones para as regras oficiais do "mundo" de Star Trek. Mas você pode então escrever sua própria fanfiction que difere, complica, ou imagina outros contextos em que esses mesmos personagens estão atuando nesse mesmo universo criativo. Crucialmente, essa atividade especulativa não esgota as possibilidades desse universo. Há uma quantidade infinita de fanfictions que podem ser escritas sem esgotar a narrativa desse universo. O mesmo vale para nosso próprio mundo. Essas intervenções não esgotam nosso sentido de mundo. Em vez disso, permitem-nos perceber que as narrativas mundiais são criadas e que nosso senso de mundo é produzido por essas narrativas.

Em uma era de crise climática e com a pandemia COVID-19, estamos cientes mais do que 
nunca de que a mudança é possível. Isso é particularmente importante se aceitarmos que nossas visões de mundo e visões futuras do futuro são baseadas em narrativas profundas que são reforçadas repetidamente em nossas culturas globais compartilhadas. Proponho que a cenográfica proporcione uma metodologia para revisitar essas narrativas mundiais e especular novas "cenas" ou mundos que nos permitam imaginar de forma diferente.

Em resumo, aqui está o manifesto que aparece dentro de Beyond Scenography e oferece um roteiro de trabalho para o poder da cenográfica na especulação de imaginários de um novo mundo:

Cenográficos irritam as ordens disciplinadas do mundo

Uma cenografia de orientação é uma cenografia do sentimento

A skenografia tem muitos legados

A cenografia não está definida; cenografia acontece

A cenografia excedeu o cenógrafo

Não há palcos sem cenográficos

Enquanto toda cenografia é cenográfica, nem tudo que é cenográfico é cenografia

Considerando que a arquitetura slow diz respeito à monumentalidade, a arquitetura fast é cenográfica

Cenográficos atingem atos de mundanização. (HANN, 2019).

Referências

AHMED, Sara. Queer Phenomenology: orientations, objects, others. Durham, NC and London: Duke University Press, 2006.

APPIA, Adolphe. L'oeuvre d'Art Vivant. Genève \& Paris: Edition Atar, 1921.

AUSTIN, John Langshaw. How to do Things with Words. Oxford: Oxford University Press, 1962.

HANN, Rachel. Beyond Scenography. New York: Routledge, 2019.
. E4: Scenographic Futures. Rachel Hann's

Youtube channel. Disponível em: < https://www.youtube.com/watch?v=uCfgS4VeMzl $>$. Acesso em: 08 jun. 2020.

HARAWAY, Donna. Staying with the Trouble; Making Kin in the Chthulucene. Durham: Duke University Press, 2016.

PAYNE, Darwin Reid. Computer Scenographics. $1^{\text {a }}$ ed. Carbondale and Edwardsville: Southern Illinois University Press, 1994.

STEWART, Kathleen. Tactile Composition. In: HARVEY, Penny; CASELLA, Eleanor Conlin; EVANS, Gillian; KNOX, Hannah; MCLEAN, Christine; SILVA, Elizabeth B.; THOBURN, Nicholas; WOODWARD, Kath. (Eds.). Objects and Materials. New York and London: Routledge, pp 775-810, 2014.

Recebido: 02/03/2020

Aprovado: $20 / 06 / 2020$

Este é um artigo de acesso aberto distribuído sob os termos de uma Licença Crea- tive Commons Atribuição 4.0 Internacional. Disponível em: <http://creative commons. org/licenses/by/4.0>. 